\title{
МАРКЕТИНГОВЫЕ АСПЕКТЫ РАЗВИТИЯ КОНКУРЕНЦИИ НА РЫНКЕ ЗДРАВООХРАНЕНИЯ
}

\section{(c) 2021 Зубарева Наталья Николаевна}

кандидат педагогических наук, соискатель, кафедра менеджмента и маркетинга

Белгородский государственный национальный исследовательский университет, Россия, Белгород

E-mail nzubareva73@mail.ru

В статье рассматриваются вопросы интеграции отрасли здравоохранения в систему рыночных высоко конкурентных отношений, проводится изучение экономических связей, объективно возникающих между организациями в процессе осуществления ими медицинской деятельности. Выявлено отличие медицинских и государственных компаний, оказывающих медицинские услуги, выступающих конкурентами на рынке здравоохранения. Целью исследования является анализ предпосылок и процесса рыночной трансформации маркетинговых стратегий медицинских компаний. Полученные данные могут быть использованы медицинскими учреждениями при разработке собственных маркетинговых стратегий и составлении соответствующих методических и практических рекомендаций в области осуществления конкурентной борьбы.

Ключевые слова: система здравоохранения, государственная и частная медицина, конкурентоспособность, конкурентная среда, участники конкурентных отношений, повышение конкурентоспособности медицинских учреждений, рынок здравоохранения.

Введение. В настоящее время уже невозможно обособить медицину от маркетинга, да и экономики в целом. Хотя раньше, когда здравоохранение было исключительно прерогативой государства, данные области не особо отличались смежностью. Маркетинг был попросту не нужен для медицинских учреждений. Нынешняя экономика здравоохранения изучает формы, методы и результаты хозяйственной деятельности медицинских организаций, ее организацию и развитие на высоко конкурентном рынке.

Материалы и методы. Можно выделить некоторые причины выделения экономики здравоохранения и медицинского маркетинга в самостоятельные полноправные области:

1. Стало очевидным, что здоровье человека представляет всё более возрастающую ценность, в том числе экономическую. По рекомендациям $\mathrm{OOH}$ благосостояние нации представляет собой систему нескольких элементов (демографические условия, пища, одежда, условия труда, занятости, образование; социальное обеспечение; человеческие свободы и т.д.), среди которых здоровью отводится особо важное место. При этом очевидно, чем больше экономически развито государство, тем лучше показатели здоровья в стране.

2. Произошел рост потребностей населения в медицинских услугах в связи с увеличени- ем численности населения, его заметным старением, изменением характера патологий, ростом хронических заболеваний и т.д., соответственно понадобились ресурсы и инструменты для удовлетворения данных потребностей.

3. В конце 20 века здравоохранение стало ресурсоемкой отраслью, и назрела проблема эффективного использования необходимых ресурсов. Здравоохранение стало использовать высокотехнологичные методы и дорогостоящее медицинское оборудование.

4. Здравоохранение стало рассматриваться как выгодная область приложения инвестиционных ресурсов и получения высоких прибылей.

5. Здравоохранение начало восприниматься как система сохранения рабочей силы, её воспроизводства, сохранения и приумножения богатства страны.

В широком спектре индустрии здравоохранения есть отдельные рынки для услуг первичной медико-санитарной помощи, больничной помощи, медицинского оборудования, фармацевтических препаратов, человеческих ресурсов, а также медицинского и сестринского образования. Поэтому отрасль здравоохранения - одна из важнейших. Конкуренция на рынке здравоохранения очень выгодна для потребителей, поскольку помогает снизить их затраты, улучшить качество и еще больше стимулирует инновации. 
В процессе оказания медицинских услуг, а также при их потреблении возникают некоторые взаимоотношения между субъектами на рынке здравоохранения. Эти отношения протекают в рамках специфической формы соперничества между врачами, медицинскими центрами по достижению наивысшей степени удовлетворения целевых потребностей пациента.

В сфере здравоохранения есть сторонники и противники конкуренции. С одной стороны, конкуренция повышает эффективность и продуктивность решений, а с другой стороны, она увеличивает чрезмерное давление и меняет ситуацию не так хорошо. Следовательно, чтобы создать лучшую отрасль здравоохранения, необходимо наличие здоровой конкуренции с упором исключительно на запросы пациентов.

Рыночная экономика ориентирована на рыночные законы (спроса, предложения, конкуренции), поэтому и развитие здравоохранения при переходе на рыночные рельсы, в свою очередь, стало опираться и руководствоваться аналогичными закономерностями. В последнее время увеличился объём оказываемых медицинских услуг (в том числе платных), возрос спрос на них, соответственно, появилась и стала совершенствоваться конкуренция на рынке здравоохранения, возникла необходимость регулирования спроса со стороны рынка и со стороны государства.
До 1990 г. в России единственным легальным способом оказания медицинских услуг было обслуживание населения государственными медучреждениями, которые, в общем-то, не конкурировали между собой (не было производственной и коммерческой необходимости). Коммерческий рынок медицины если и существовал, то только в виде «теневых платежей» врачам. Постепенно совершенствование законодательства и рост спроса на услуги врачей и клиник способствовали формированию и развитию современного рынка платных медицинских услуг, обострилась конкуренция на рынке здравоохранения за счет появления на нем большого числа коммерсантов. В качестве конкурентов на рассматриваемом рынке стали выступать как государственные, так и частные медицинские организации. Конкуренция между клиниками при этом прослеживается не только за пациентов, но и за врачей. И всё чаще победителями в этой конкурентной борьбе выходят именно «частники».

Обсуждение. На рисунке 1 представлена динамика объема рынка платных медицинских услуг в России за 2006-2020 гг. согласно данным РБК, свидетельствующая о том, что с каждым годом коммерциализация медицинской деятельности набирает обороты. Так, к примеру, за последние 10 лет объем платных сервисов вырос почти на треть.

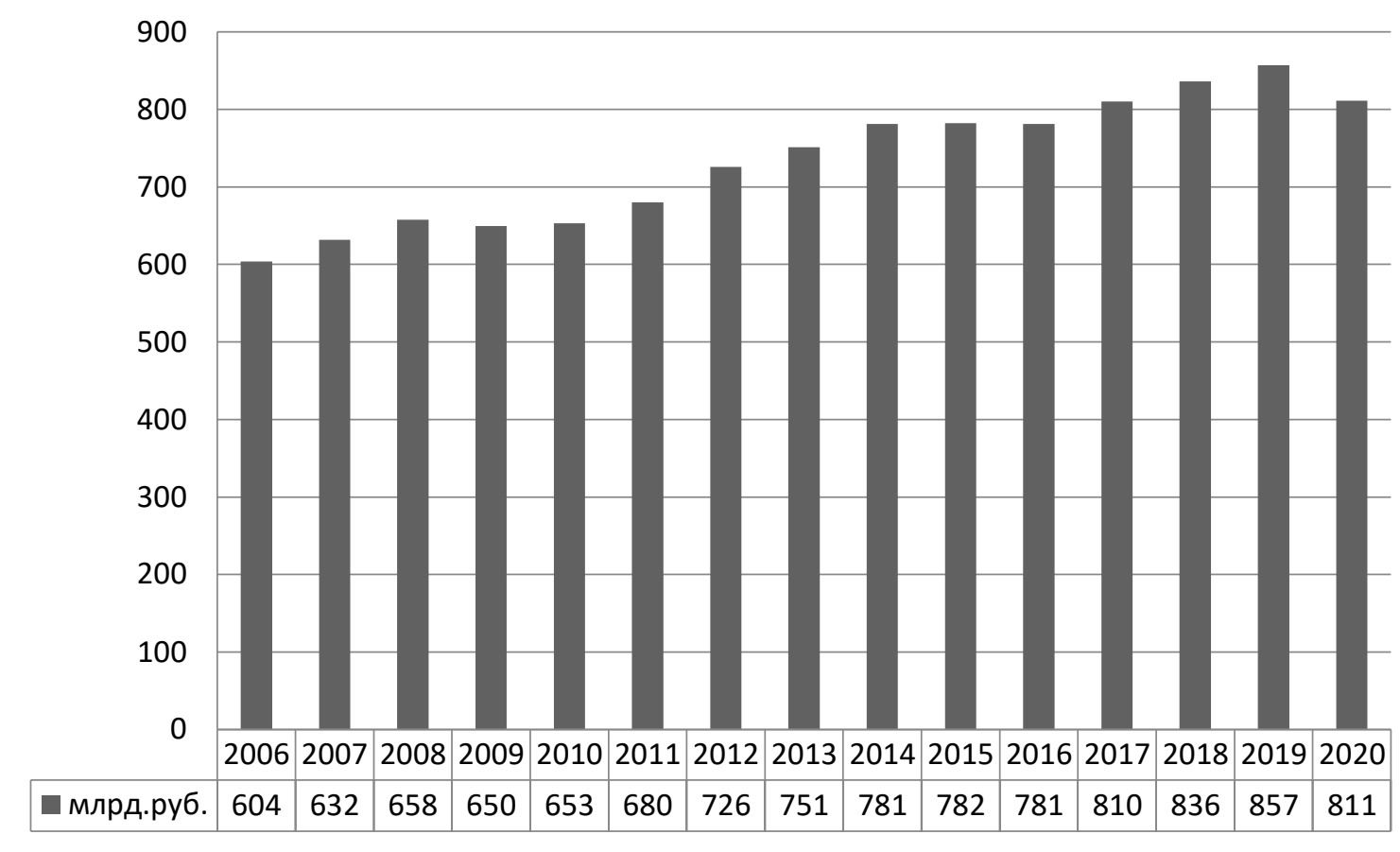

Рисунок 1. Динамика объема рынка платных медицинских услуг в России [10] 
Аналитики PwC (международная сеть компаний, предлагающих услуги в области консалтинга и аудита) считают, что уже к 2025 году объем рынка коммерческой медицины в России превысит триллион рублей. Но это при позитивном сценарии, когда рынок будет расти на 9,6\% в год.

Неоднозначное влияние на развитие рынка коммерческой медицины оказала пандемия (на графике видно, что в 2020 году доходы частных клиник упали с 857 млрд. руб. до 811 млрд. руб.). С одной стороны, затраты россиян на медицинские услуги выросли и среднее количество приемов у врачей увеличилось. Но с другой стороны, самих потребителей платных услуг больше не стало.

Население обращалось и обращается в коммерческие учреждения для проведения диагностического обследования, поскольку провести подобную диагностику в государственных клиниках возможно только в соответствии со строгими показаниями. Поэтому драйверами роста конкурентных преимуществ частных клиник в период пандемии стали именно лабораторная диагностика, КТ и телемедицина.

В структуре рынка платных медицинских услуг около 70\% занимает легальный сектор рынка. Очевидно, что продолжает уменьшаться доля теневых платежей, рынок становится более прозрачным. Объем теневого сектора за последние 10 лет сократился в 2,4 раза (рис. 2).

На конец 2020 года на территории РФ функционировали более 3000 сетевых частных кли- ник. Сетевая лабораторная, как уже было обозначено, диагностика выступает локомотивом развития конкуренции на рынке коммерческой медицины. Это связано с рядом причин:

- удобство для потребителей (в вопросе скорости оказания услуг, сервиса);

- пункт приема биоматериалов открыть проще и дешевле, чем клинику;

- возможность для медцентров работать по франчайзингу.

В свою очередь можно заметить внушительное сокращение числа государственных лечебно-профилактических учреждений за последнее десятилетие (рис. 3.).

Связано это с «оптимизирующими» реформами, направленными на укрупнение государственных больниц и поликлиник. Только вот годы реформ доказали, что без кардинального пересмотра модели здравоохранения, отказа от политики «бездумной» оптимизации российская государственная медицина в обозримом будущем имеет все шансы стать «здравоЗахоронением», навсегда потеряв шанс приблизиться по качеству к стандартам развитых стран мира.

На дальнейшее развитие рынка платных медицинских услуг будет влиять укрепление конкурентных преимуществ частных организаций, включая:

- расширение направлений медицинских услуг;

- внедрение телемедицинских консультаций;

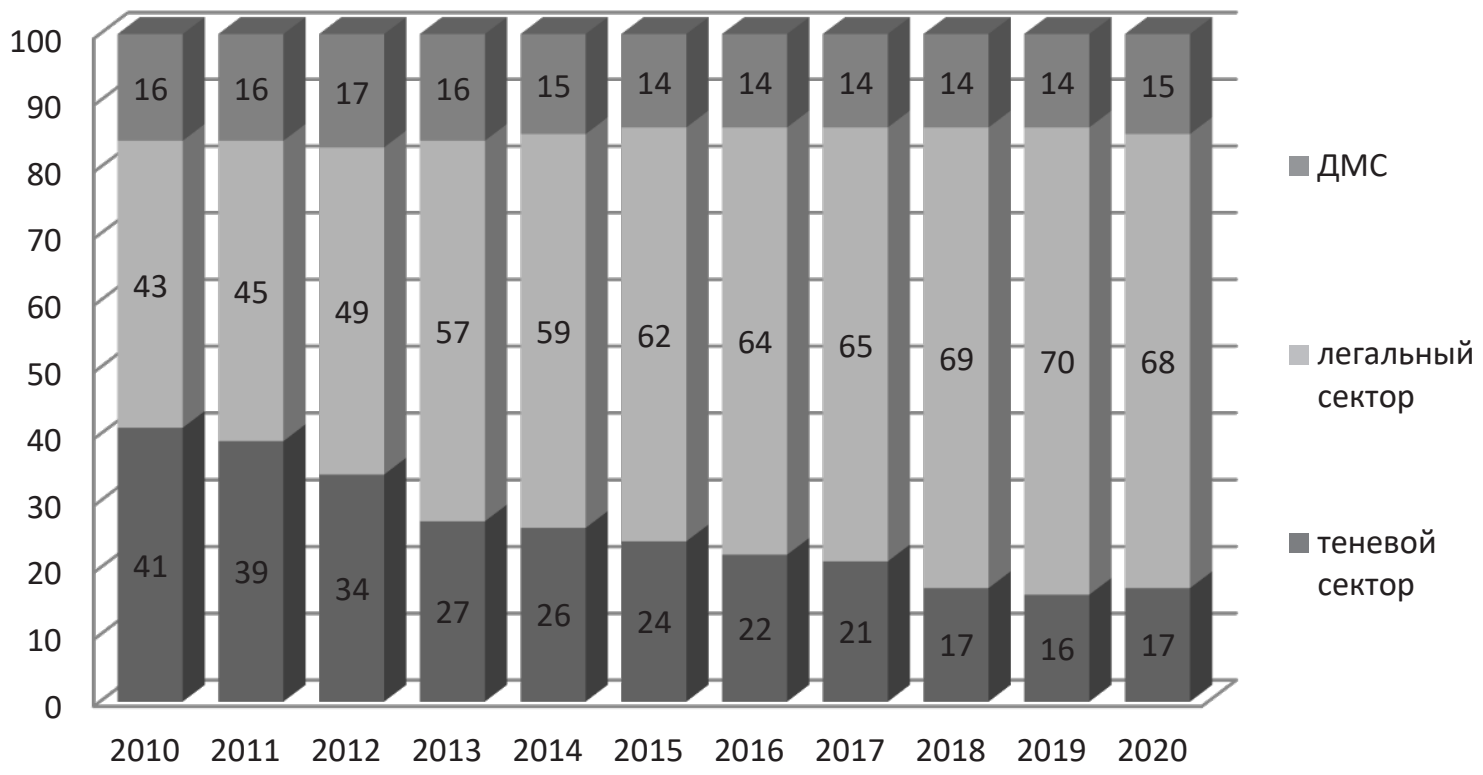

Рисунок 2. Структура рынка платных медицинских услуг в России, \% [10] 


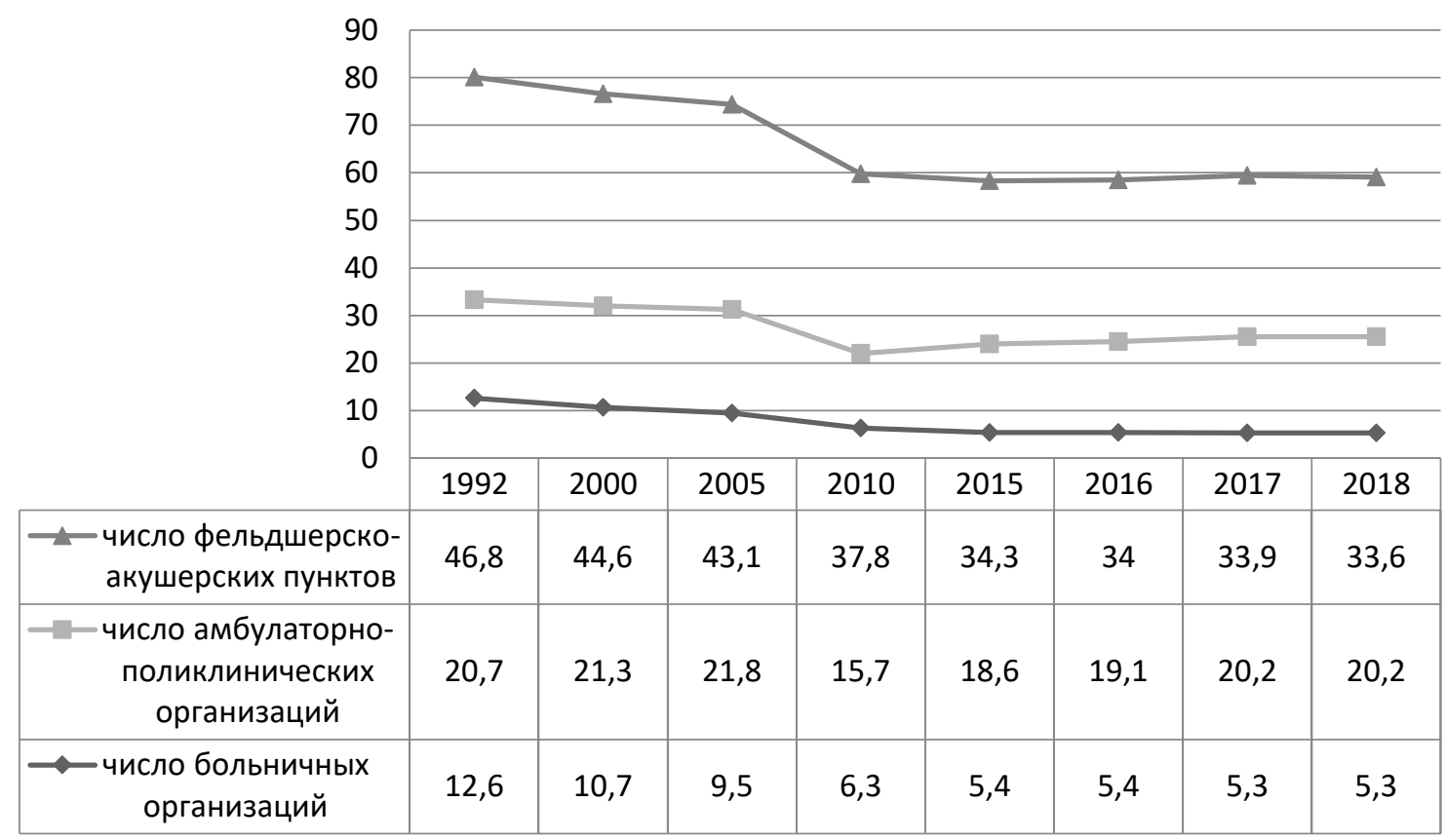

Рисунок 3. Динамика численности государственных ЛПУ в России, тыс. шт. [10]

- высокий уровень квалификации врачебного персонала;

- повышение качества обслуживания и так далее.

Толчок к появлению конкуренции и развитию коммерческой медицины дает само государство. Принимаемые решения порой настолько неадекватны и оторваны от реальности, что иногда заставляют предполагать, что ведется целенаправленное уничтожение создававшейся десятилетиями системы здравоохранения. Место «оптимизируемых» в процессе реформ здравоохранения (а на самом деле ликвидируемых или стагнирующих) государственных медицинских учреждений логично занимает коммерческая медицина. Сильные стороны коммерческих клиник проистекают из самой их природы - отсутствие коррупции и бюрократии, позволяет быстро реагировать на запросы рынка.

Каждая частная клиника делает акценты на те или иные направления медицинской деятельности, совершенствуя их с учетом опыта руководства, потребностей рынка и наличия команды специалистов. Частная медицина активно развивается, появляется всё больше игроков на рынке здравоохранения, который становится высоко конкурентным. На данный момент одной из отличительных черт платной медицины выступает высокотехнологичная оснащенность клиник и лабораторий, однако и государствен- ные клиники не отстают в этом от своих конкурентов, ежегодно обновляя свое оборудование в рамках действующих государственных программ.

Существует множество рынков здравоохранения, на которых конкуренция может быть эффективной, но для поддержки этой конкуренции необходима правильная политика государства. Экономисты предлагают три типа реформ политики, которые повысят конкуренцию в сфере здравоохранения и улучшат функционирование рынка.

- сократить или отменить политику, которая поощряет консолидацию или препятствует выходу на рынок и конкуренции.

- усилить антимонопольное правоприменение, чтобы федеральные и государственные антимонопольные органы могли действовать эффективно для предотвращения и устранения вреда для конкуренции.

- создайте агентство, отвечающее за мониторинг и надзор за рынками здравоохранения, и дать этому агентству право гибко вмешиваться, когда рынки здравоохранения не работают.

Медицинская помощь относится к услугам первой необходимости. Даже при крайне низкой покупательной способности человек не откажется от обращения к врачу. Поэтому медицина всегда будет востребованной сферой. И вот сейчас как раз время «расцвета» коммерческой 
медицины, которую можно назвать равноправным конкурентом (пока что еще не полным заменителем) государственным лечебным учреждениям на российском рынке здравоохранения.

Можно ли сказать, что частная медицина однозначно опережает государственную в конкурентной борьбе? Если судить только по внешнему впечатлению, частные клиники, конечно, более комфортны для пациентов. Здесь практически не бывает очередей, доступны все нужные специалисты и целый ряд диагностических исследований, время приёма пациента составляет 30-40 минут, а не 5 минут, как в районных поликлиниках. Но значит ли это, что государственная медицина окончательно отстала от коммерческой по всем статьям? Ответить однозначно сложно.

Справедливости ради стоит отметить и то, что не всё так гладко и легко и у организаций, оказывающих медицинские услуги на коммерческой основе. Не секрет, что хотя платная медицина и становится всё более популярной, часть пациентов относится к частным центрам с недоверием. И порой это вполне оправдано например, до сих не во всех медучреждениях пациентам выдают кассовые чеки, не везде заключают договоры с клиентами клиник. Кроме того, пациенты жалуются, что доктора навязывают им дорогостоящие обследования, которые впоследствии оказываются ненужными.

K сожалению, правовая инфантильность, когда некоторые частные клиники работают полулегально, не ведут медицинскую документацию, не укомплектованы необходимым оборудованием действительно имеет место. Есть даже такие клиники, владельцы которых далеки от медицины и относятся к ней исключительно как к способу извлечения прибыли, а не помощи людям. Из-за подобных отдельных прецедентов некоторые пациенты начинают негативно воспринимать платную медицину в целом. Ещё одна проблема - беззащитность перед законодательной «неразберихой». Складывается впечатление, что нормативно-правовую базу в этой сфере создают люди, которые вообще не понимают, что происходит в медицине. Принимается множество бессмысленных и неисполнимых законов, что предоставляет широкие возможности для увеличения административного давления на бизнес.

Вообще, понятия «государственная» и «частная» медицина - это понятия взаимодополняю- щие и стимулирующие. Считается возможным, даже необходимым сотрудничество этих двух структур. Частная и государственная медицина нужны гражданам в равной степени, просто у каждой свои задачи и возможности.

В последние годы много говорят о государственно-частном партнёрстве (ГЧП) в медицине. Суть его в том, что коммерческое учреждение входит в систему ОМС, а затем государство через Фонд обязательного медицинского страхования закупает у него определённый набор услуг - ими затем бесплатно пользуются нуждающиеся больные. Если бы государственночастное партнёрство в нашей стране наладилось, это было бы очень удобно для пациентов. Когда человек приходит в клинику и не думает, частная она или государственная, он везде получит помощь.

Заключение. Отрасль здравоохранения сталкивается с множеством сложных проблем. Влияние усиления конкуренции на качество здравоохранения и системные затраты до сих пор неясно. Кроме того, данные о взаимосвязи между качеством медицинской помощи, предоставляемой клиентам, и системными затратами на оказание медицинской помощи не являются обширными и достаточно изученными. Информация о факторах, способствующих удовлетворению запросов потребителей, не совсем понятна. Различные исследования дают противоречивые выводы. Мы предполагаем, что неоднозначность в отношении влияния конкуренции на качество, стоимость и удовлетворенность пациентов частично возникает из-за того, что эти вопросы ранее рассматривались изолированно. Взаимосвязанный характер этих вопросов требует, чтобы они рассматривались одновременно.

Подводя итог, стоит отметить, что потребители медицинских услуг и продуктов получают выгоду от конкуренции на рынке здравоохранения, ведь именно она создает стимулы для постоянного улучшения продукта и способствует более высокому уровню обслуживания. Что еще более важно, конкуренция может помочь держать цены под контролем. Конкурентные рынки существуют, когда у потребителей есть несколько вариантов покупки и выбора с прозрачными ценами. Ограничение количества продуктов или вариантов услуг - или неопределенность в отношении относительных цен - уменьшает преимущества конкуренции для потребителей. 


\section{Библиографический список}

1. Бондаренко В.А. Актуальные проблемы создания и внедрения маркетинговых инноваций // Научнометодический электронный журнал Концепт. 2015. № 2. С. 16-20.

2. Бондаренко В.А. Апология маркетинга в кризисных условиях // Маркетинг в России и за рубежом. 2010 . № 4 . С. 3-9.

3. Бондаренко В.А. Изменение потребностей индивидов и модели их поведения в обществе потребления // Практический маркетинг. 2014. № 4 (206). С. 14-19.

4. Воронкова Е.А., Кублин И. М. Проблемы фармацевтического бизнеса при реализации лекарственных препаратов через Интернет // Экономическая безопасность и качество. 2018. № 3 (32). С. 36-40.

5. Воронов А.А., Валькович О.Н. Рыночный подход - единственно реальный путь повышения качества и эффективности медицинского обслуживания в современной России // Проблемы управления здравоохранением. 2002. № 2. С. 44-47.

6. Воронов А.А., Валькович О.Н. Рыночный подход путь повышения качества медицинского обслуживания // Здравоохранение Российской Федерации. 2001. № 5. С. 6-8.

7. Карамова А.С., Чуваткин П.П. Конкуренция в российском здравоохранении // Вестник Академии знаний. 2017. № 4 (23). С. 91-97.

8. Кублин И.М., Кузнецов О. И., Кислов А. В. Взгляд на проблему инновационного развития в здравоохранении // Современная экономика: проблемы и решения. 2013. № 4 (40). С. 53-59.

9. Кублин И.М., Оноприйчук Б. С. Диверсификация как фактор устойчивого развития предприятия в рыночных условиях // Поволжский торгово-экономический журнал. 2010. № 4. С. 58-64.

10. Рынок частной медицины в России. URL: https://marketing.rbc.ru/articles/11332/

11. Степченко, Т.С. Комплекс маркетинга в здравоохранении / Т. С. Степченко // Новая наука: Проблемы и перспективы.-2016. - № 115-1.- С. 236-238.

12. Управление территориями в конкурентной рыночной среде: Учебное пособие / В.А. Руденко, Т. С.Попова, П.В. Горлачев [и др.].- Краснодар, Новация, 2021._- 270 с. - ISBN 9785001790563. 